COO/4051-45
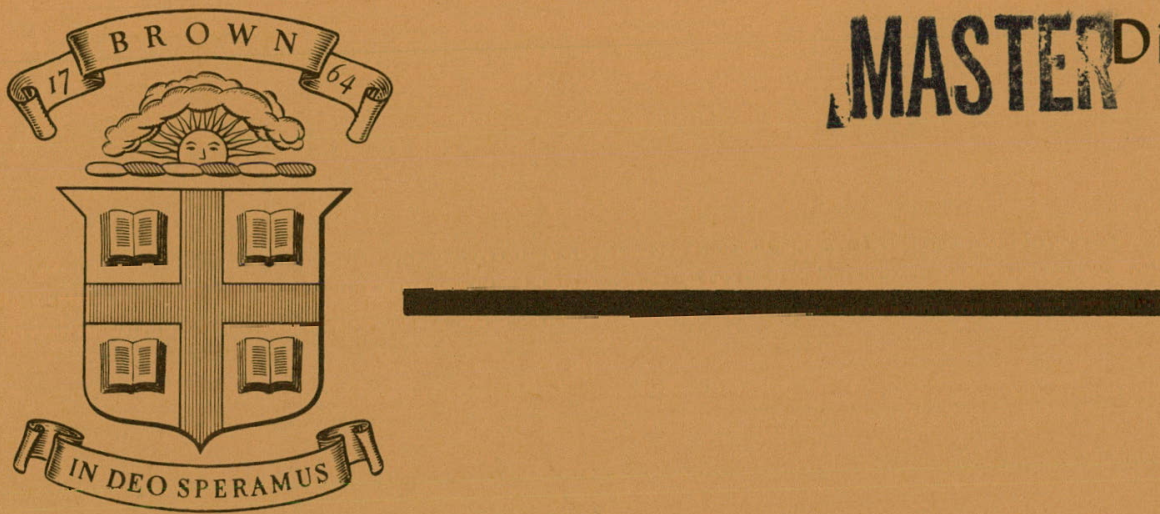

$$
\begin{aligned}
& \text { BROWN UNIVERSITY } \\
& \text { PROVIDENCE, R. I. }
\end{aligned}
$$

\title{
AVAILABILITY: THE CONCEPT AND ASSOCIATED TERMINOLOGY
}

Second Law of Thermodynamics Workshop

George Washington University

August 14-16, 1979

Joseph Kestin

U. S. Department of Energy Contract EY-76-S-02-4051.A001

Report No. CATMEC/32 


\section{DISCLAIMER}

This report was prepared as an account of work sponsored by an agency of the United States Government. Neither the United States Government nor any agency Thereof, nor any of their employees, makes any warranty, express or implied, or assumes any legal liability or responsibility for the accuracy, completeness, or usefulness of any information, apparatus, product, or process disclosed, or represents that its use would not infringe privately owned rights. Reference herein to any specific commercial product, process, or service by trade name, trademark, manufacturer, or otherwise does not necessarily constitute or imply its endorsement, recommendation, or favoring by the United States Government or any agency thereof. The views and opinions of authors expressed herein do not necessarily state or reflect those of the United States Government or any agency thereof. 


\section{DISCLAIMER}

Portions of this document may be illegible in electronic image products. Images are produced from the best available original document. 


\section{NOTICE}

This report was prepared as an account of work sponsored by the United States Government. Neither the United States nor the Uniled States Department of Fnergy, nor any of their employees, nor any of their contractors, subcontractors, or their employees, makes any warranty, express or implied, or assumes any legal liability or responsibility for the accuracy, completeness, or usefulness of any information, apparatus, product or process disclosed or represents that its use would not infringe privately owned rights. 
AVA ILABILITY: THE CONCEPT AND ASSOCIATED TERMINOLOGY

Joseph Kestin, Professor of Engineering Brown University, Providence, RI 02912
Thepared as an account of work Une United Slates Government. Neither the Enerd stes nor the United Siates Department of Encor nor any of their employees, nor any of their any wors, subcontractors, or their employees, makes

any warranty, express or implied, or assumes any legal liability of responsibijity for the accuracy, completeness or usefulness of any information, apparatus, product of process disclosed, or represents that its use would not infringe privately owned rights.

\section{Second Law of Thermodynamics Workshop George Washington University August 14-16, 1979}

\section{Session I}

Tues: Aug. 14, 1979

11:00 AM - 12:00 Noon

Providence, June 1979 
1. Historical introduction $\ldots \ldots \ldots \ldots \ldots \ldots \ldots \ldots \ldots \ldots \ldots \ldots \ldots \ldots \ldots \ldots \ldots \ldots$

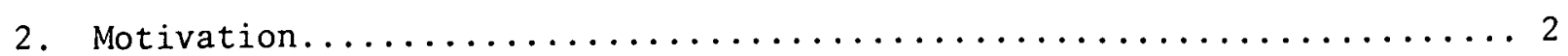

3. Model of the atmosphere: the passive environment $\ldots \ldots \ldots \ldots \ldots \ldots$

4. Man-made systems $\ldots \ldots \ldots \ldots \ldots \ldots \ldots \ldots \ldots \ldots \ldots \ldots \ldots \ldots \ldots \ldots$

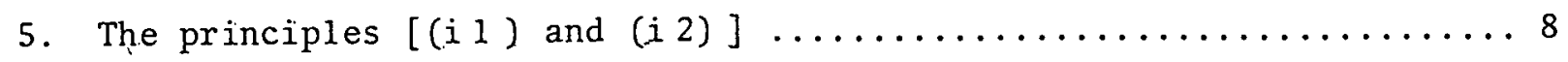

6. Systems interacting with passive environment through rigid

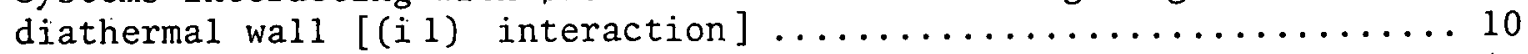

7. Extension to interaction through deformable wall [(i 2)

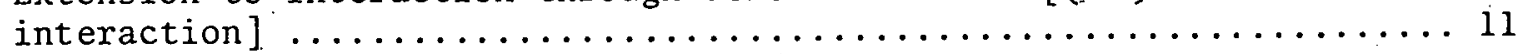

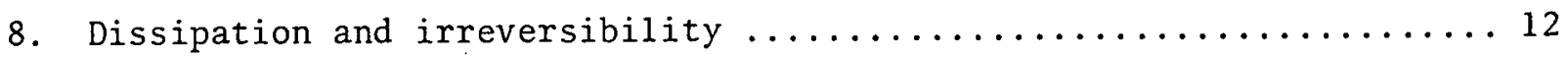

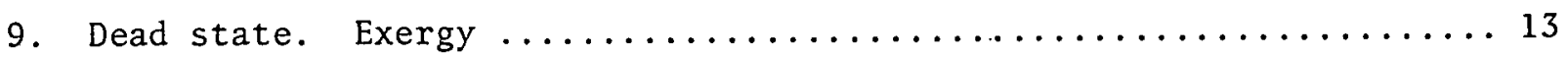

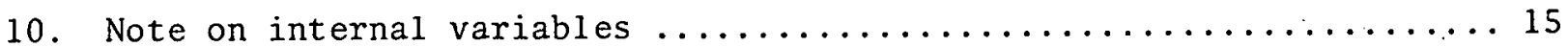

11. Systems interacting with passive environment through semipermeable

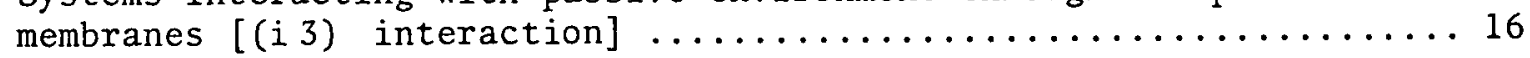

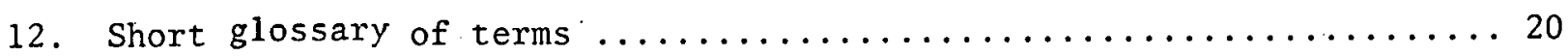

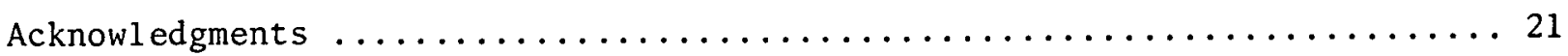

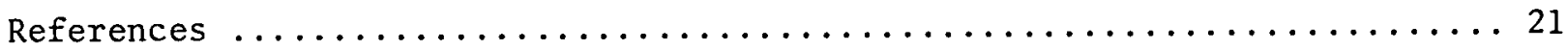

\section{List of Figures}

Figure 1. Passive environment (model of terrestrial atmosphere) ....... 4

Figure 2. Notation for open flow system, Fl $\ldots \ldots \ldots \ldots \ldots \ldots \ldots \ldots \ldots$

Figure 3 . Idealized engine for mass transfer $\ldots \ldots \ldots \ldots \ldots \ldots \ldots \ldots \ldots$ 


\author{
AVAILABILITY: THE CONCEPT \\ AND ASSOCIATED TERMINOLOGY \\ Joseph Kestin, Professor of Engineering \\ Brown University, Providence, RI 02912
}

\title{
Abstract
}

After a brief historical introduction, the paper proceeds to derive expressions for the available work of a thermodynamic system while the latter interacts with the passive environment. The passive environment is modelled as a union of three idealized reservoirs, one each of energy, volume and matter. The available work is defined as the optimum amount--largest or smallest--exchanged in the circumstances, given a prescribed initial and final state of the system. Two types of system are studied: closed systems and open flow systems, and the interaction is progressively enlarged to include, in three steps, the transfer of heat, the transfer of work and the transfer of matter. Available work is the difference between the exergy of states 1 and 2 , the exergy of a state being defined as the optimum work achievable against a final state which is one of equilibrium with the surroundings. It is shown that exergy so defined is not a unique quantity for a given system and state, because it also depends on the kind of interaction permitted and, therefore, on the kind of equilibrium achieved.

Exergy and not energy is found to represent the preferred measure of a system's "capacity to perform work".

Remarks are made about the contemporary terminology of this field, and regrets are expressed concerning the present-day proliferation of terms.

\section{Historical introduction}

Availability, conceived in its broadest sense, is one of those concepts- not infrequent in thermodynamics--which has been discovered and rediscovered independently by a string of physicists and engineers. Many writers trace this concept to M. Gouy (1889) [1], many others to J.W. Gibbs $(1873,1875)[2,3]$. Some [4] see its beginning in P.G. Tait (1868) [5], J.C. Maxwell (1871) [6] and Lord Kelvin (1879) [7]. The concept was certainly known to and used by $A$. Stodola $(1898,1905)[8,9]$ and to M.E. Jouguet (1907) [10], both of whom quote Gouy. Halfway across, the cause of availahility, and the closely related concept of exergy, was taken up by J.H. Keenan (1932) [11] who refers to G. Darrieus (1930) [12], and later by H.D. Baehr (1962) [13] who based much of his work on Z. Rant (1956) [14] and F. Bosnjakovic (1935) [15]. R.B. Evans (1969) [16] re-introduced the term for chemical work and mixing first mentioned by J.W. Gibbs. A line of development which is largely unknown in the West is represented by the untranslated treatises of J. Szargut (1965)[17] and J. Madejski (1977) [18]. The concept is presented clearly in the recent textbook of V.A. Kirillin, V.V. Sychev and A.E. Sheindlin (1976) [19].

This is not the place to sort out priorities or to present an historically researched account of the fits and starts in the development of this and related 
concepts. An excellent historical essay is contained in R.W. Haywood's [4] Appendix 4 and in J. Szargut's treatise [17].

The fact that we are now holding a conference on available work more than one hundred years after the first appearance of this idea in the scientific literature signifies that its importance was slow to emerge. The excessive complexity of many expositions, the absence of crisp descriptions of the systems considered in the argument and the traditional clinging to analysis by cycles have blurred the essentially simple message. This accounts for the fact that many equations written down by some authors are tantalizingly different from those written down by others, even though, on first sight, we expect them to be identical. Some of the blur is semantic in nature and is due to the fact that no clearly organized terminology has evolved--not surprising in the face of such an uneven history of development. At one stage I intended to list the terms used by the many authors on the subject in order to distill from them a set that would meet with least resistance. I found this impractical and reluctantly join the long line of my predecessors, each of whom has set up his own vocabulary. I shall do this as I go along, but must warn the reader that my meaning is not always the same as that of another expositor of the subject. A glossary has been added as Section 12 .

Clearly enough, I claim no originality or priority of discovery. My sole aim is to give a simple, straightforward, but logically coherent statement of the ideas and the motivation for their wider adoption in the future than they. have enjoyed in the past. I similarly refrain from considering detailed applications which have been developed in great abundance $[13,15,17,19]$.

\section{Motivation}

The set of concepts which we discuss under the broad heading of "available work" serves to formalize several general observations concerning industrial processes in thermodynamic terms and so to make way for statements concerning their efficiency. The function of thermodynamics is to establish the most general principles which allow us to judge what the optimum is in given circumstances, and what is the maximum that we can extract from our natural resources. Since they are exhaustible, we wish to "conserve" them, that is to use them sparingly as we proceed to achieve our economic goals.

The first observation is that a11 industrial processes occur in the terrestrial atmosphere which, for all practical purposes, is an inexhaustible source (or sink) of: energy, work, and matter. The energy of the atmosphere can be increased (or decreased) by an exchange of heat. The atmosphere can perform an unlimited amount of work, or have an unlimited amount of work performed on it, by expanding or contracting volumes against its pressure. Finally, certain chemical species present in it can be withdrawn and all others can be exhaled into it.

In addition to being inexhaustible, we assume that energy, work, and matter can be obtained from or dumped into the atmosphere at no cost (in the economic sense). 
The second observation is that industrial processes are possible by virtue of the fact that there exist in nature substances which are not in equilibrium with the atmosphere. These are the natural resources. In contrast with the atmosphere, we attach an economic value to our natural resources and are, particularly recently, acutely aware that they are not inexhaustible. This is the consequence of the fact that by forcing such natural resources to change their thermodynamic state in an industrial installation, we can produce work. This work (or "energy" in the contemporary media) is considered most valuable (in the economic sense).

The third observation is that the most we can do in any circumstances is to change the thermodynamic state of the resource to one of equilibrium with the atmosphere, that is to reduce it to a state of equilibrium with the surroundings. When this happens, no further useful processes are possible, and for this reason we call such a state passive with respect to the surroundings or the dead state. We surmise that the corresponding amount of work transferred outside the system will be optimum, subject to the fulfillment of certain conditions, here to be discovered.

The fourth observation is that the work made available outside one system at the expense of a natural resource can, in turn, in another system, be utilized to transform the state of certain other substances present passively in the atmosphere and so to confer on them an enhanced economic value.

In all cases, the concept of a "change in the thermodynamic state" includes the transformation of the nature of substances through chemical reactions.

In the spirit of $\mathrm{H}$. Callen's Thermodynamics [20], we recognize that the manipulation of internal or external constraints causes a generally irreversible process to occur as a result of which subsystems within the system, or the system and the passive surroundings, transfer some extensive quantity (volume, $V$, energy, $U$, quantities, $n_{i}$, of matter) and tend to equalize a corresponding intensive property. This equalization is not achieved if the process is arrested at some intermediate state.

The type of interaction that occurs between the system and the passive surroundings depends on the character of the system's boundary, that is, on the partition placed between the system and the atmosphere. Following the usual practice, we shall consider adiabatic versus diathermal walls, rigid versus deformable walls, and impermeable versus semi-permeable or completely pervious walls.

We can now anticipate that the amount of work (positive or negative) obtainable (or required) in given circumstances will depend on:

(a) The thermodynamic characteristics of the atmosphere.

(b) The type of system considered.

(c) The types of interaction permitted between the system and the atmosphere.

(d) The initial and final state of the system.

(e) The rate of dissipation produced within the system. 


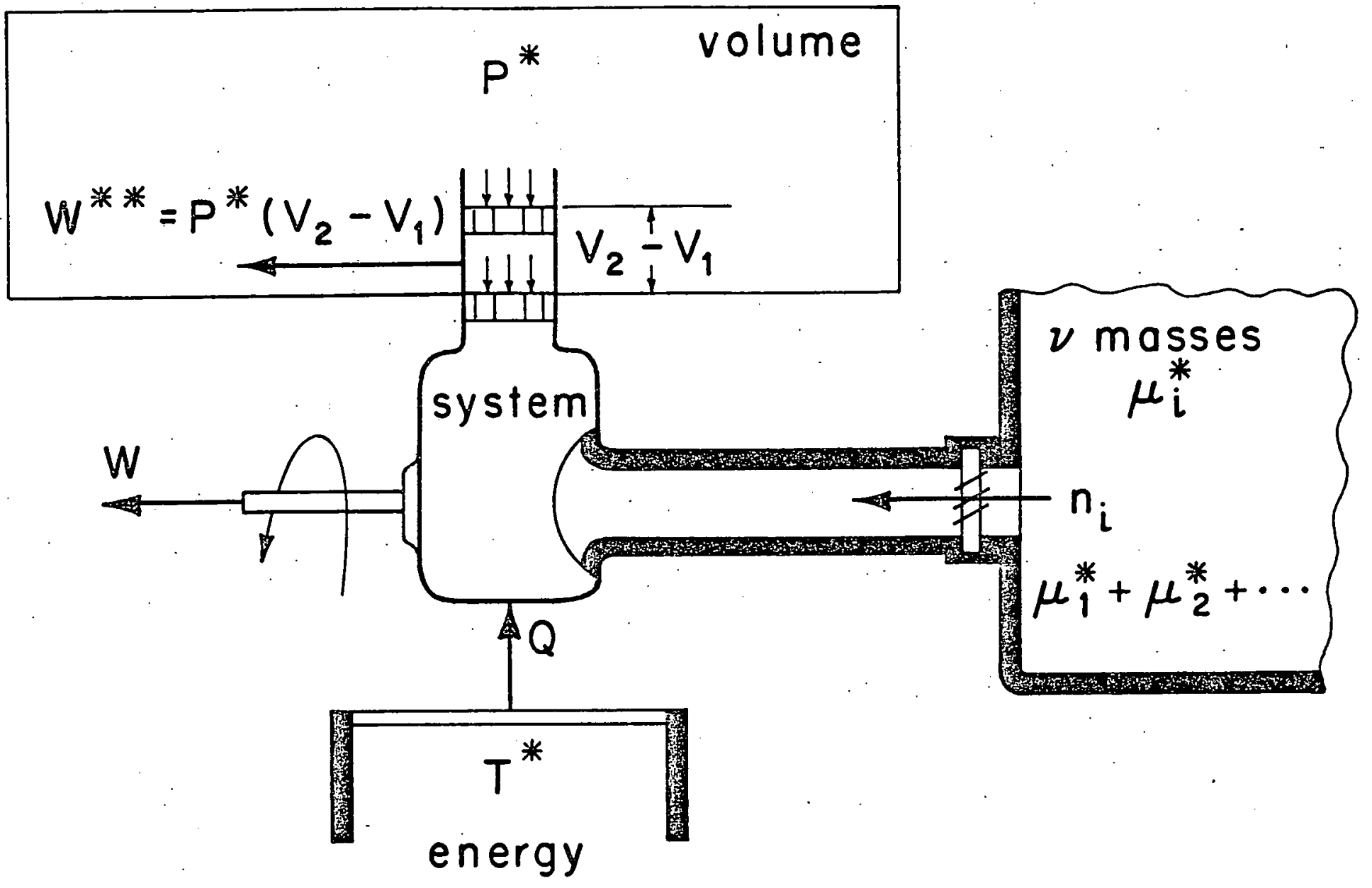

rigid, adiabatic, impermeable

= rigid, diathermal, impermeable

the rigid, diathermal, semipermeable

Wس deformable (floating piston)

Figure 1. Passive environment (model of terrestrial atmosphere). 
In the light of these remarks, we recognize that the optimum work, which we shall call available work cannot be described by a single formula and that the detailed nature of each formula must be adapted to circumstances. Nevertheless, it is feasible to subsume all possible cases under a small number of categories. which, in a manner sanctified by long use in thermodynamics, will rest on idealized models of atmosphere, system, and allowed type of interaction. Naturally enough, these models constitute no more than convenient conventions.

3. Model of the atmosphere: the passive environment

The model of the atmosphere, for which we propose the term passive environment, is conceived as a union of three very large reservoirs, an energy reservoir, a volume reservoir and a reservoir of mass containing $v$ chemical species. The intensive state of the passive surroundings is described by

temperature $\mathrm{T}^{*}$ for the energy reservoir pressure $\mathrm{P}^{*}$ for the volume reservoir

$\nu$ chemical potentials $\mu_{i}^{* *}$ for the mass reservoir.

We picture that the conjugate extensive variables, $\mathrm{U}^{* *}, \mathrm{~V}^{* *}$ and $\mathrm{n}_{i}^{* *}$ are so large that the reservoirs remain in internal equilibrium during interaction with man-made devices, or, what amounts to the same, that the relaxation times for a return to equilibrium are much shorter for the passive environment than for the system under consideration. Consequently, the reservoirs forming the passive environment are capable of performing only reversible processes.

The three hypothetical reservoirs are depicted schematically in Figure 1, each. shown interacting. with the system. The energy reservoir exchanges heat $Q$, the volume reservoir exchanges work $W^{* *}$, and the mass reservoir exchanges matter, $n_{i}$, along a number of channels, only one of which is shown. We adopt a sign convention consistent with that for the system, and stipulate

$Q>0 \quad$ when transferred into the system and out of the passive environment

$W^{* *}>0$ when transferred out of the system and into the passive environemnt

$W>0$ when made available by system for use outside it

$n_{i}>0$ when transferred into the system and out of the passive environment.

In what follows, we shall allow our systems to undergo the following sequence of interactions :

(i1) Transfer of heat

(i2) Transfer of heat and work

(i3) Transfer of heat, work, and mass.

$$
\}
$$

Each interaction causes the thermodynamic extensive properties of the atmosphere to change, and we now write down the corresponding expressions. For the energy reservoir: 


$$
\Delta \mathrm{U}^{* *}=-\mathrm{Q} ; \quad \Delta \mathrm{V}^{* *}=0 ; \quad \Delta \mathrm{S}^{* *}=-\mathrm{Q} / \mathrm{T}^{*}
$$

For the volume reservoir:

$$
\Delta U^{* *}=0 ; \quad \Delta V^{* *}=-\left(V_{2}-V_{1}\right) ; \quad \Delta S^{* *}=0 ; \quad W^{* *}=P^{*}\left(V_{2}-V_{1}\right) .
$$

Here the symbols without the asterisk refer to the system proper. The mass reservoir must be treated as an open system, and we shall revert to it in Section 11. In a11 cases, the system proper is capable of producing (or absorbing) a quantity of work $W$ which, unlike $W^{* *}$, can be exploited for the attainment of our economic goals (or which must be paid for if $W<0$ ).

In writing down equations we make no distinction between mass units and mole units, and interpret the symbol $\mathrm{n}_{j}$ as a measure of the quantity of matter. The insertion of the appropriate quantities is merely a matter of unit conversion which can be conveniently handled at the time when numerical results are desired.

\section{Man-made systems}

From a practical point of view, we can classify all systems that we wish. to consider into

and

prime movers $P$ characterized by $W>0$,

The latter consume work to effect a change in state.

Except for Sections 6 and 8 and an occasional remark, we shall conduct our discussion in terms of prime movers, $P$, noting that all equations apply to receivers, $R$, and require merely a change in the sign of all quantities.

From the point of view of applications, we shall consider two further classes of systems: closed systems (Cl) and flow systems ( $F()$ ). The closed system was depicted schematically in Figure 1. The open flow system is shown sketched in Figure 2. In both cases the symbolic shaft reminds us that the system produces utilizable work, $W$, or consumes it at some other system's expense.

The state of the closed system must, clearly, be described by more than just two variables. We envisage that it consists of a number of internally cons trained subsystems, and that a process $1 \rightarrow 2$ is released in it by the manipulations of some internal constraints. Thus; the symbols $U, H, S$, etc., used for it denote sums of the corresponding extensive properties of all subsystems. Intensive properties of the closed system do not occur in the present theory. Specifically, we do not require them to be uniform across the subsystems; they do, however, belong in the specification of the state of the subsystems.

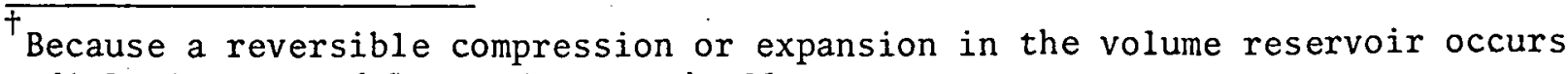
adiabatically and hence isentropically.
} 


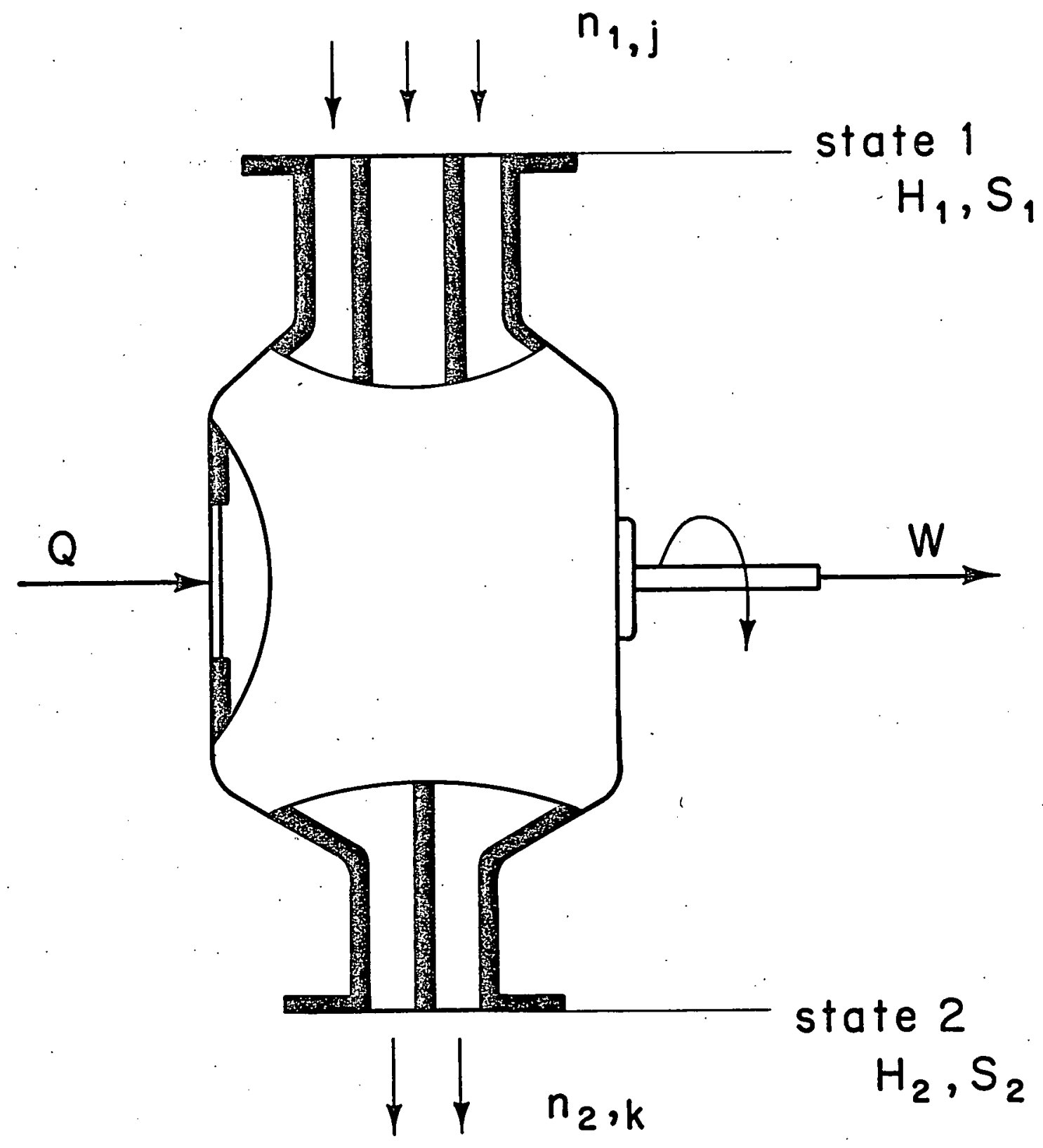

Figure 2: Notation for open flow system, Fl. 
As far as the open system is concerned, we assume steady-state operation, so that

$$
Q=\dot{Q} t ; \quad W=\dot{W} t ; \quad N_{i}=\dot{n}_{i} t \text {, etc. }
$$

Here $t$ is an arbitrary time interval. With this in mind, it is seen that all equations for open systems may be written interchangeably as rate equations or equations for a process $1 \rightarrow 2$.

In most cases which follow, we shall show one inlet channel and one exit channel. It is, however, understood that the number (generally different) of inlet channels and exit channels is arbitrary and that sums over all inlet or exit cross-sections are implied. This, and the adoption of the summation convention of repeated indices, $j$ for the inlet, $k$ for the exit, and $i$ for the general case, will simplify the exposition.

The preceding classification reduces our task to the derivation of formulae of work for six cases:

$$
\begin{array}{lll}
(\mathrm{i} 1): \mathrm{Cl} ; & \mathrm{Fl} . \\
(\mathrm{i} 2): \mathrm{Cl} ; & \mathrm{Fl} . \\
(\mathrm{i} 3): \mathrm{Cl} ; & \mathrm{Fl} .
\end{array}
$$

It is, actually, apparent that the case (i 2) does not exist if only steadystate flow systems are considered. Consequently, only five distinct cases occur.

As a final convention we assume that the resource for $P$ operations is given to us at state 1 . The resource need not consist of a single substance; it may appear in the form of a mixture of unrelated streams, as in combustion. Each subsystem, however, will occur at a definite intensive state and will be characterized by temperatures $T_{1, j}$, pressures $P_{1, j}$ and a set of internal variables (composition, extent of chemical reaction, etc., all translatable into a set $A_{1}, j$ of affinities for each stream). In the reverse, or $R$ operation, the same is true, because a complex installation may be employed to produce several mixed or separated streams.

5. The principles [(i 1$)$ and (i 2$)]$.

In order to develop our equations and to draw the appropriate conclusions, we have recourse to three principles. We shall write them down here for the interactions ( $i 1$ ) and (i 2), reserving the case (i 3) for Section 11. The three principles are:

Conservation of mass: This is always implied, but is kept in the background. There will be no need to write it down explicitly.

Conservation of energy: This takes the form of the First Law of thermodynamics. Specifically:

$$
\begin{array}{ll}
\text { Cl: } & Q-W=\mathrm{U}_{2}-\mathrm{U}_{1} \\
\text { Fl: } & \mathrm{Q}-\mathrm{W}=\mathrm{H}_{2}-\mathrm{H}_{1} .
\end{array}
$$


When flow systems are analyzed it may become necessary to include the kinetic and potential energy of the streams at 1 and 2. In such cases there is no need to change anything except to assign a proper interpretation to the symbols $\mathrm{H}_{1}$ and $\mathrm{H}_{2}$ in eqn. (5b), namely

$$
\begin{aligned}
& \mathrm{H}_{1}=\dot{\mathrm{n}}_{1, j}\left(\mathrm{~h}_{1, j}+\frac{1}{2} v_{1, j}^{2}+\mathrm{gz}{ }_{1, j}\right) t \\
& \text { (sum over } \mathrm{j} \text { ), } \\
& \mathrm{H}_{2}=\dot{\mathrm{n}}_{2, \mathrm{k}}\left(\mathrm{h}_{2, \mathrm{k}}+\frac{1}{2} v_{2, \mathrm{k}}^{2}+\mathrm{gz} \mathrm{z}_{2, \mathrm{k}}\right) \mathrm{tz} \\
& \text { (sum over } \mathrm{k} \text { ). }
\end{aligned}
$$

Here $V$ is the stream velocity and $z$ is its elevation over the reference elevation $z^{*}=0$ assigned to the passive environment.

Some authors write equation $(5 b)$ in the shorthand form

$$
Q-W=-\dot{\mathrm{n}}_{\mathrm{i}} \mathrm{h}_{\mathrm{i}} \mathrm{t}
$$

(sum over $i$, quantities positive for $i=j$ and negative

$$
\text { for } i=k ; \text { ), }
$$

or

$$
Q-W=-\sum \mathrm{H}_{i},
$$

with an obvious interpretation for $\mathrm{H}_{4}$. However, though convenient in certain contexts, we shall not need to use this compact notation in the present paper.

Here, later in this section, as well as in the case of closed composite systems, it is necessary to carefully normalize the constants in all extensive properties, such as $U, H, S$, etc. [23].

Conservation of entropy: We write it in the form

$$
S_{2}-S_{1}+\Delta S^{* *}=\theta \text {. }
$$

Here $S_{1}, S_{2}$ refer to the system and are to be interpreted as

$$
s_{1}=\dot{n}_{i, j} s_{i, j} \text {. and } s_{2}=\dot{n}_{2, k} s_{2, k} t
$$

(sums over $\mathrm{j}, \mathrm{k}$ ). ,

in the case of a flow system. The entropy change of the passive environment is represented by $\Delta S^{* *}$ and defined in eqns. $(2 \mathrm{a}, \mathrm{b})$. The entropy production or entropy generation term is denoted by $\theta$.

It is evident that eqn. (9) is a statement of the Second Law applied to an isolated system and conceived as a union of the system proper and the passive environment. The difference between the initial and final entropy of such an 
adiabatic system, defined here as entropy production, must be positive or zero depending on whether the process $1 \rightarrow 2$ under consideration is irreversible or reversible. Thus

$$
\theta \geq 0 \quad(>0 \text { irrev.; }=0 \text { rev. })
$$

6. Systems interacting with passive environment through rigid diathermal wall only [(i 1$)$ interaction]

We now consider our two systems, $\mathrm{Cl}$ and $\mathrm{Fl}$, operating between two prescribed states 1 and 2 , so that an irreversible process $1 \rightarrow 2$ results. At first we limit attention to systems which are allowed to interact with the passive environment through rigid diathermal walls only. In the case of the open $F l$ system, we picture the existence of mass reservoirs which are artificially maintained and independent of the passive environment. This is the (i 1) interaction listed in (1).

Both forms, (5a) and (5b), of the First Law indicate, as every student of thermodynamics is sure to know, that the work $W$ is not uniquely prescribed by the states 1 and 2 . A decrease in work performed $(W>0)$ through inefficiency is reflected as a decrease in heat extracted from the passive reservoir if $Q>0$ or an increase in the amount rejected to it, if $Q<0$. When $R$ systems are involved, $W<0$, and the amount of work consumed, $|W|$, increases with. $Q$, decreasing if $Q>0$ and increasing if $Q<0$. Restrictions on the work $W$ can only be consequences of the Second Law.

A simple elimination of $Q$ from eqns. (5a) and (5b) and (9) with $\Delta S^{* *}=-Q / T^{*}$ from eqn. (2a,b) leads to the results that

$$
\begin{aligned}
& \text { for } C l: W=U_{1}-U_{2}-T^{*}\left(S_{1}-S_{2}\right)-T^{*} \theta \text {, } \\
& \text { for Fl: } W=H_{1}-H_{2}-T^{*}\left(S_{1}-S_{2}\right)-T^{*} \theta .
\end{aligned}
$$

Since by the second part of the Second Law, eqn. (11), we must have $\theta \geq 0$, it follows that the quantities

$$
\begin{aligned}
& \text { for } C l: W^{\circ}=U_{1}-U_{2}-T^{*}\left(S_{1}-S_{2}\right), \\
& \text { for Fl: } W^{\circ}=H_{1}-H_{2}-T^{*}\left(S_{1}-S_{2}\right),
\end{aligned}
$$

are as large as they can be in the circumstances and that they can only be achieved by the hypothetical reversible process $1 \rightarrow 2$. Moreover, $w^{\circ}$ in each case is uniquely defined by the states 1 and 2 of the system and the temperature $T^{*}$ of the passive environment. Finally, the optimum quantity is independent of the details of the reversible process $1 \rightarrow 2 .^{+}$By contrast, the entropy production $\theta$ in eqns. $(12 a, b)$ is not a thermodynamic property, varies

TMuch of the superfluous complexity of many presentations of the subject stems from the fact that the authors calculate $w^{\circ}$ along specifically selected reversible paths $1 \rightarrow 2$. There is nothing wrong with this procedure, because any reversible path will do, but the derivation unnecessarily overwhelms the reader. 
from irreversible path $1 \rightarrow 2$ to irreversible path $1 \rightarrow 2$, and can only be determined if the full process details are known.

Many textbooks, including my own [21], refer to $w^{\circ}$ as the maximum work. It is preferable to use the alternative expression available work for it, because $W^{0}$ is not a true maximum with respect to $\theta$. When $W>0$, $W^{0}$ is a supremum, i.e. the largest value over the open interval $0<\theta<+\infty$. When $W<0, \quad\left|W^{0}\right|$ is an infimum, or the smallest value over the same open interval. At no point does the derivative of $w^{0}$ vanish with respect to the variable parameter $\theta$.

The two sets of equations, $(12 a, b)$ and $(13 a, b)$ can be contracted into one by defining a new thermodynamic function, $E$, which we shall call exergy, reserving a fuller discussion for Section 9. Thus we define

$$
\begin{aligned}
& \text { for } C l: E=U-T^{*} S-\bar{E}, \\
& \text { for } F l: E=H-T^{*} S-\bar{E},
\end{aligned}
$$

where $\bar{E}$ denotes an additive constant to be selected rationally also in Section 9. This allows us to write

$$
\begin{aligned}
& W=E_{1}-E_{2}-T^{*} \theta, \\
& W^{\mathrm{o}}=E_{1}-E_{2},
\end{aligned}
$$

for the (i 1) interaction.

\section{Extension to interaction through deformable wall [(i 2) interaction].}

It is easy to extend the preceding results to include interaction through a deformable system boundary. As long as the $\mathrm{Fl}$ system is assumed to be in steady-state, and as long as a receptacle of substances at pressure $\mathrm{P}_{2}$ is available, eqns. (12b), (13b) and (14b) continue to apply. The only modification is the appearance of work

$$
W^{* *}=P^{*}\left(V_{2}-V_{1}\right)
$$

which is now transferred from system to passive environment. When $W^{* *}>0$, this work cannot be put to good use. When $w^{* *}<0$, this work is free. For these reasons we subtract it from $W$ and display it separately. In order not to complicate matters, we retain the symbol $\mathrm{W}$ for this utilizable work, and replace eqns. (12a) and (13a) with

$$
\begin{aligned}
& W=U_{1}-U_{2}+P^{*}\left(V_{1}-V_{2}\right)-T^{*}\left(S_{1}-S_{2}\right)-T^{*} \theta \\
& W^{0}=U_{1}-U_{2}+P^{*}\left(V_{1}-V_{2}\right)-T^{*}\left(S_{1}-S_{2}\right) .
\end{aligned}
$$

It is clear that the new definitions

$$
\begin{array}{ll}
\text { for } C l: & E=U+P^{*} V-T^{*} S-\bar{E}, \\
\text { for } F l: & \bar{E}=H-T^{*} S-\bar{E},
\end{array}
$$


ailow us to retain the validity of the equations

$$
\begin{aligned}
& W=E_{1}-E_{2}-T^{*} \theta, \\
& W^{o}=E_{1}-E_{2},
\end{aligned}
$$

also for the (i 2) interaction.

The difference between the definitions in eqns: (19a) and (19b) should be noted with respect to the alternative forms:

$$
\begin{array}{ll}
C l: & E=U+P^{*} V-T^{*} S-\bar{E} \\
F l: & E=U+P V-T^{*} S-\bar{E},
\end{array}
$$

in which the pressure $\mathrm{P}\left(\mathrm{P}_{1}, \mathrm{P}_{2}\right)$ instead of $\mathrm{P}^{*}$ is operative in $\mathrm{Fl}$ as against $\mathrm{Cl}$. This is understandable in the light of our assumptions: a rigid boundary in the former case and a deformable boundary in the later.

\section{Dissipation and irreversibility}

The most general pair of equations $(20 \mathrm{a}, \mathrm{b})$ together with the two forms $(5 a, b)$ of the First Law, allow us to represent the entropy production as

$$
T^{\star} \theta=W^{0}-W=Q^{0}-Q
$$

where $Q^{\circ}$ is heat transferred during the hypothetical reversible process $1 \rightarrow 2$. The quantity

$$
\Phi=T^{*} \theta=W^{0}-W=Q^{0}-Q
$$

occurs in the literature under a variety of designations: "uncompensated heat", "dissipation", "work dissipated" (into heat), "work lost". Similarly, the quantity $\theta$ which we call entropy production (of process $1 \rightarrow 2$ ) appears as "entropy generation", as well as "entropy generated" or "produced" during the irreversible process.

Any one of these quantities can be used as an absolute measure of irreversibility for process $1 \rightarrow 2$ in the presence of our passive environment. Some writers prefer to use the following relative measures of irreversibility: the utilization factor or relative efficiency for $P$ operation

$$
n=\frac{W}{W^{\circ}}=1-\frac{\Phi}{W^{\circ}}=1-\frac{T^{*} \theta}{W^{\circ}} \quad(\leq 1)
$$

the utilization factor or relative efficiency for $R$ operation

$$
n=\frac{\left|W^{0}\right|}{|W|}=\frac{1}{1+\Phi /\left|W^{0}\right|}=\frac{1}{1+T^{*}{ }_{\theta} /\left|W^{0}\right|} \text {. }
$$


The utilization factor, $\dot{n}$, is sometimes called "effectiveness".

The profusion of essentially equivalent concepts and the even greater proliferation of terms to name them is confusing, but it is a "fact of life". Any discussion about the intrinsic merits of one as against another is barren, and all that matters is that their origin, unity and mutual relationships should be recognized. At best one can express a preferencet and hope for a recognized standardization.

The general equation (22) can also be given the form

$$
\theta=\frac{E_{1}-E_{2}-\omega}{T^{*}},
$$

which often proves very convenient. Some authors [e.g. 17,19] call the preceding equations the Gouy-Stodola theorem. Any one of the equivalent forms is an expression of the general dissipation theorem of thermodynamics [24].

\section{Dead state. Exergy}

In all our preceding considerations, we have assumed that state 1 as well as state 2 was given. This led us to the conclusion that the best that we can do is to arrange for the process to be reversible, when the available work $W^{0}$ will be produced or consumed. We now ask which of all possible processes is optimal, when only state 1 is prescribed. As long as state 2 fails to reach temperature and pressure equilibrium with the passive environment, it is possible to devise a further process $2 \rightarrow 3$ and to augment $W^{0}(W>0)$ on condition, evidently, that the entropy production for this process is non-negative. This possibility ceases when all subsystems of system $C l^{*}$ and all exit streams of system $\mathrm{Fl}$ reach a temperature $\mathrm{T}^{*}$ and a pressure $\mathrm{P}^{*}$. In the latter case, the elevation $z_{\mathrm{k}^{*}}^{*}=0$ must be reached, and the velocity must be reduced to $v_{\mathrm{k}}^{*}=0$. Following J. ${ }^{H}$. Keenan, we call this the dead state. We further adopt the convention

The exergy of a system in a given state 1 is defined as the available work obtainable when state 2 is the dead state.

In this definition it is clearly understood that the nature of the system has been defined together with the particular kind of equilibrium with the passive environment demanded of the dead state.

$\mp$

I prefer $\theta$ (entropy production), as an absolute measure, because of its utility in continuum thermodynamics [22], and $\eta$ (utilization factor), as a relative measure, by force of engineering habit, even though two separate definitions are needed for it. Names for (concrete) physical quantities ending in "ility" (availability, irreversibility, etc.) should be avoided because they get confused with the names for the related (abstract) concepts. 
It is an immediate consequence of this definition that we must adopt the convention

$$
E^{*}=0 \quad \text { (dead state), }
$$

which, in turn, fixes the additive constant introduced in Section 7 at

$$
\begin{array}{ll}
C l: & E=\mathrm{U}^{*}+\mathrm{P}^{*} \mathrm{~V}^{*}-\mathrm{T}^{*} \mathrm{~S}^{*}=\mathrm{G}^{*} \\
\mathrm{Fl}: & E=\mathrm{H}^{*}-\mathrm{T}^{*} \mathrm{~S}^{*}=\mathrm{G}^{*},
\end{array}
$$

or

$$
E=G^{*} \text {. }
$$

In words, we find that the additive constant is equal to the Gibbs free energy. ${ }^{\dagger}$ of the system when all its parts (or exit streams) are in temperature and pressure equilibrium with the passive environment.

With this convention, we now write explicitly

$$
\begin{array}{ll}
\text { Cl: } & E=U+\mathrm{P}^{*} \mathrm{~V}-\mathrm{T}^{*} \mathrm{~S}-\mathrm{G}^{*} \\
\text { Fl: } & E=\mathrm{H}-\mathrm{T}^{*} \mathrm{~S}-\mathrm{G}^{*},
\end{array}
$$

in replacement of eqns. $(19 a, b)$

Colloquialiy speaking, the exergy of a system can be taken as a measure of its capacity to perform work when coupled in a prescribed way to a conveniently. defined passive environment. Like many concepts in this field, much metaphysics has been composed on its behalf, because its essential dependence on convention is often forgotten. Much has also been written about exergy versus. energy on the erroneous view (still perpetuated in elementary textbooks) that energy represents a system's "capacity to perform work". No such intrinsic quantity exists, and energy cannot a fortiori pretend to be it. The we11-worn example of a perfect gas at temperature $\mathrm{T}^{*}$ and three pressures, $\mathrm{P}_{1}>\mathrm{P}^{*}, \mathrm{P}_{2}=\mathrm{P}^{*}$, and $\mathrm{P}_{3}<\mathrm{P}^{*}$ confronts us with three systems of equal (but completely undefined) energy in the thermodynamic sense. The systems at $\mathrm{P}_{1}$ and $\mathrm{P}_{3}$ have non-zero exergies and definite capacities to perform work (in the sense explained above), whereas system $P_{2}$ possesses no such capacity. Similarly, the "capacity to perform work" of a geothermal brine cannot be measured by its enthalpy difference, $h(T)-h\left(T^{*}\right)$, as is sometimes done, whereas its specific exergy serves the purpose admirably $[25,26]$.

It is the Helmholtz free energy $F^{*}$ for (i 1) in eqn. (14a) of Section 6. 
Many authors use the term "availability function" for $E$. Some feel the need to give a name ("anergy"t). to the term $T^{*}\left(S-S^{*}\right)$. I do not belieye that this is any more useful than giving different names to exergy depending on whether (i 1) or (i 2) equilibrium is discussed or whether we are interested in a closed or open system. After al1, we do not feel the need to give different names to energy, enthalpy or entropy to match a particular context.

It seems to me that the real culprit is the idea, bequeathed to us by force of habit from phlogiston days, that somehow our machinery "converts" energy from "one form to another", energy being taken sometimes as the internal energy of the system and sometimes as the "heat content" or enthalpy of a stream measured above an agreed level. The facts do not support this mode of thinking, because energy is not a weightless indestructible substance, and no absolute value of energy can be assigned to a single state of a system [27].

The exergy of pure substances can be represented graphically as an area in a T,S or a segment in an H,S diagram. It is also possible to employ exergy as a coordinate in $E, S$ diagrams. Details can be found in $[11,13,15,17,18,19$, 25].

10. Note on internal variables

The optimal available work, woo, defined by

$$
W^{\circ 0}=E_{1}-E^{*}=E_{1}
$$

together with the definitions $(29 a, b)$, or the equivalent definition for the case $C l$ (i 1$)$, is still not unique, in spite of the fact that the mode of interaction with a specified passive environment has been laid down. This has to do with the fact that to a given pair of values, $\mathrm{T}^{*}$ and $\mathrm{P}^{*}$, of temperature and pressure there may correspond a large string of dead states if the system contains, as it usually does, a set of internal constraints. Internal constraints may take different forms, such as, for example, a very slow reaction rate in a chemical system.

The theory of thermodynamic stability [28] provides a clear clue to the quest for the optimum among all the optimal values of $W^{\circ 0}=E_{1}$ : it is that value for which $G^{*}$ is a minimum at $T^{*}=$ const, $\mathrm{P}^{*}=$ const, that is that state which. results when "all internal constraints have been removed". Even this rule is not quite unambiguous. It is clear enough in the presence of chemical reactions, but much depends on what we consider feasible in given circumstances. Sometimes the final composition attainable is subject to practical limitations and a knowledge of what could be attained after all internal constrains have

† Sometimes defined as "energy which cannot be transformed into exergy". This is semantically acceptable only if $\mathrm{T}^{*}\left(\mathrm{~S}_{-} \mathrm{S}^{*}\right)^{*} 0$. There exist galvanic cells (and many uther systems) for which $\mathrm{T}^{*}\left(S-S^{*}\right)<0$ and, therefore, $E=\left(U-U^{*}\right)+\left|T^{*}\left(S-S^{*}\right)\right|>U-U^{*}$ (assuming here that $\left.V=V^{*}\right)$. 
been lifted is not helpful in assessing the degree of imperfection of an economically or technologically realizable installation. For this reason, the dead state must be defined in some detail in concrete cases. ${ }^{\dagger}$

When a minimum of $G^{*}$ is sought, it must never be forgotten that all extensive variables contain arbitrary constants. These disappear from the accounting when differences are formed only if they have been properly normalized between the initial state and the dead state [23]. The importance of this remark, already made in Section 5 , cannot be overemphasized.

11. Systems interacting with passive environment through semipermeable membranes [(i 3) interaction]

The last step that remains to be taken is the calculation of the additional work, $W^{\prime}$, that can be gained by allowing an exchange of mass between the system and the mass reservoir of the passive environment. The driving force for each species is the difference between the chemical potential of that species in the system and its chemical potential in the environment created by the different state and composition of the system and the environment.

For convenience we perform the calculation for the species as they exist in the system after expansion to a state of unconstrained equilibrium at $\mathrm{P}^{*}$ and $\mathrm{T}^{*}$ characterized in the preceding section. We recognize that this last step is identical for $C l$ and $F l$ systems, because an identical transfer of mass is involved in both.

The method of derivation can be explained with reference to. Fig. 3 which shows a container at $\mathrm{P}^{*}, \mathrm{~T}^{*}$ representing the system as a semipermeable membrane for species $k$. Outside this membrane, the species exists at the membrane pressure $\tilde{\mathrm{P}}_{\mathrm{k}}^{*}$ and its specific Gibbs function is identical with the chemical poten$\operatorname{tial} \mu_{\mathrm{k}}^{*}$.

Thus,

$$
\mu_{k}^{*}=g_{k}\left(\tilde{P}_{k}^{*}, T^{*}\right)
$$

and by the homogeneity theorem of the Gibbs free energy, the free energy of the system is

$$
\mathrm{G}^{*}=\mu_{\mathrm{k}}^{*} \mathrm{n}_{\mathrm{k}},
$$

$+$

To give an absurd example: Should we require that the metal of an industrial installation must be oxidized and dispersed in the passive environment?

${ }^{5}$ As in [21] we make a distinction between the membrane pressure of a general system and the partial pressure of a perfect gas. Some authors use the term "partial pressure" in the more general sense, $i$ ie. as a synonym for our membrane pressure. 


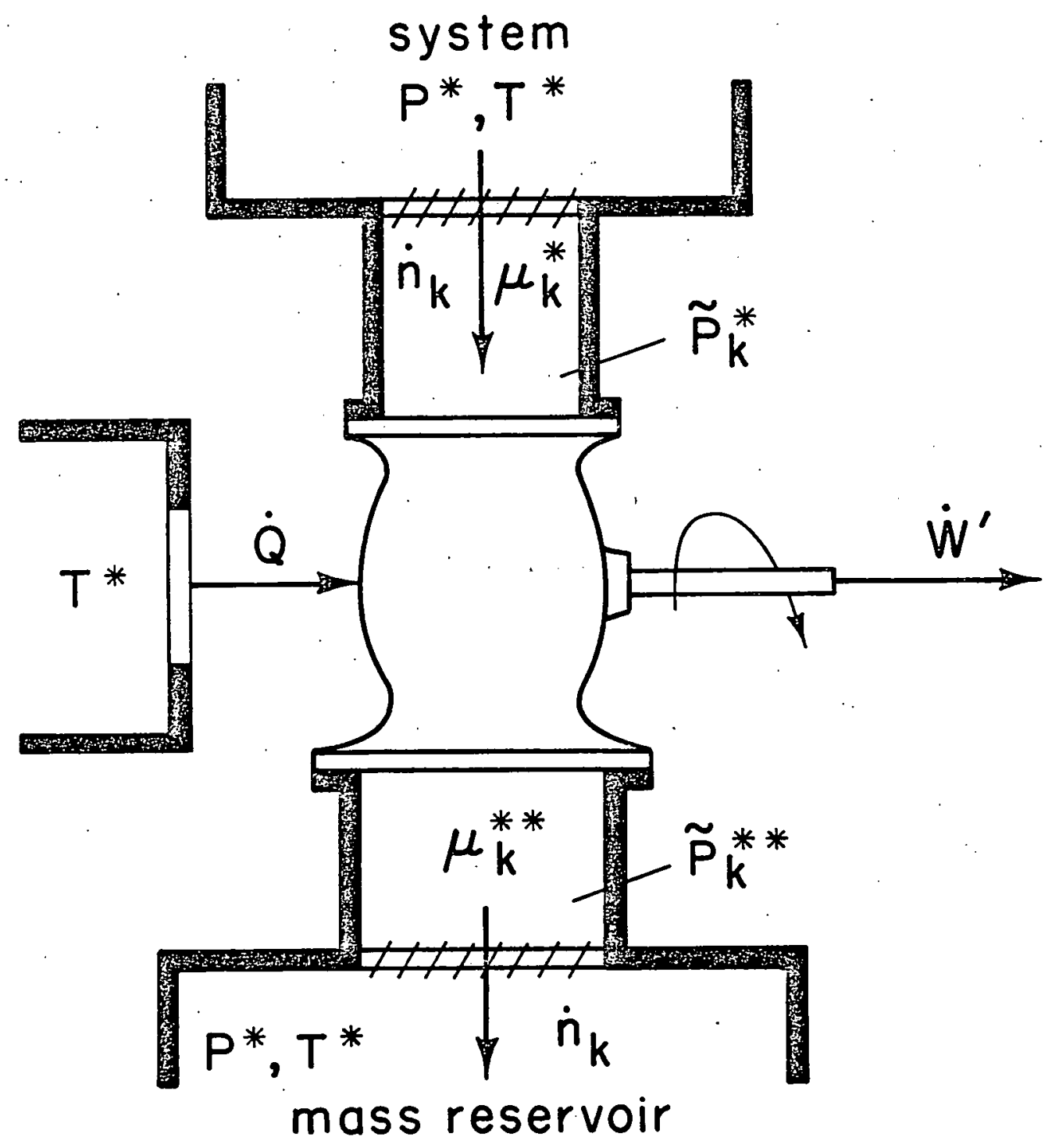

Figure 3. Idealized engine for mass transfer. 
because

$$
\stackrel{\mu^{*}}{*}=\left(\partial \mathrm{G}^{*} / \partial \mathrm{n}_{\mathrm{k}}\right) \mathrm{T}^{*}, \mathrm{P}^{*}
$$

The species $k$ is now allowed to pass through a flow device performing the additional work $W_{k}^{\prime}$, exchanging the additional heat $Q_{k}^{\prime}$, and changing its state to one of membrane equilibrium with the mass reservoir of the passive environment. The latter has a different composition. Therefore, the membrane pressure $\tilde{\mathrm{P}}_{\mathrm{k}}^{\star *}$ is different from $\tilde{\mathrm{P}}_{\mathrm{k}}^{*}$ and the chemical potential $\mu_{\mathrm{k}}^{* \star} \neq \mu_{\mathrm{k}}^{\star}$.

We continue by writing the energy balance and entropy balance equations for the sum over all species, and prefer to employ the rate form. The First Law yields

$$
\dot{Q}^{\prime}-\dot{W}^{\prime}=\dot{n}_{k}\left(h_{k}^{* *}-h_{k}^{*}\right)
$$

The Second Law is somewhat more complex, because we must account for the entropy carried by the streams $\dot{\mathrm{n}}_{\mathrm{k}}$. These are

$$
-\dot{\mathrm{n}}_{\mathrm{k}} \mathrm{s}_{\mathrm{k}}^{*} \text { and }+\dot{\mathrm{n}}_{\mathrm{k}} \mathrm{s}_{\mathrm{k}}^{* *}
$$

giving

$$
-\frac{\dot{\mathrm{q}}}{\mathrm{T}^{*}}+\dot{n}_{\mathrm{k}}\left(\mathrm{s}_{\mathrm{k}}^{* *}-\mathrm{s}_{\mathrm{k}}^{*}\right)=\dot{\theta} \cdot
$$

where $\dot{\theta} '$ is the additional entropy production rate. Elimination of the heat rate $\dot{Q}^{\prime}$, in a manner analogous to that in Section 6 , leads to the result that

$$
\dot{W}^{\prime}=\dot{n}_{k}\left(h_{k}^{*}-T^{*} s_{k}^{*}\right)-\dot{n}_{k}\left(h_{k}^{* *}-T^{*} s_{k}^{* *}\right)-T^{*} \dot{\theta}^{\prime} .
$$

Rewriting for a finite time, $t$, and noting that

$$
\mathrm{h}_{\mathrm{k}}^{*}-\mathrm{T}^{*} \mathrm{~s}_{\mathrm{k}}^{*}=\mu_{\mathrm{k}}^{*} \text { and } \mathrm{h}_{\mathrm{k}}^{* *}-\mathrm{T}^{*} \mathrm{~s}_{\mathrm{k}}^{* *}=\mu_{\mathrm{k}}^{* *} \text {, }
$$

as well as that

$$
\mathrm{n}_{\mathrm{k}_{\mathrm{k}}{ }_{\mathrm{k}}^{*}}=\mathrm{G}^{*}
$$

we can transform equation (36) to

$$
W^{\prime}=G^{*}-n_{k} \mu_{k}^{*}-T^{*} \theta^{\prime} \text {. }
$$

In this manner we recognize that the additional term in exergy due to mass transfer is 


$$
W^{\prime O}=G^{*}-n_{k}^{\mu *} k^{*}
$$

The last term in eqn. (38) cannot be contracted to represent the Gibbs function of the passive mass reservoir because the $n_{k}$ denote the quantities of each species as they are present in equilibriumt at $\mathrm{P}^{*}$ and $\mathrm{T}^{*}$ in the system. However, the specific Gibbs free energy

$$
g_{k}\left(\tilde{P}^{* *}, T^{*}\right)=\mu_{k}^{* *}
$$

is that which is characterized by the intensive state of the atmosphere. ${ }_{*}$ n other words, the $\mu_{\mathrm{k}}^{*}$ are intensive properties of the system, whereas the $\mu_{k}^{* *}$ are intensive properties of the passive environment.

Summing with the terms in eqns. $(29 a, b)$, we obtain the final expressions

$$
\begin{array}{ll}
C l: & E=\mathrm{U}+\mathrm{P}^{*} \mathrm{~V}-\mathrm{T}^{*} \mathrm{~S}-\mathrm{n}_{\mathrm{k} \cdot \mathrm{k}}{ }^{* *} \\
\text { Fl: } & E=\mathrm{H}-\mathrm{T}^{*} \mathrm{~S}-\mathrm{n}_{\mathrm{k}} \mathrm{H}_{\mathrm{k}}^{* *}
\end{array}
$$

The available work of a process $1 \rightarrow 2$ is still given by eqn. (20b) and the actual work by eqn. (20a). The presence of mass transfer (by diffusion, across phase boundaries into the atmosphere, etc.) causes the final state 2 to be different than it would be in its absence, for a prescribed state 1 . Even in the ideal, reversible case, the work $W^{\prime} \circ$ represented by two terms in eqn. (38), namely

$$
W^{\prime} 0=n_{k}\left(\mu_{k}^{*}-\mu_{k}^{* *}\right)
$$

may turn out to be negative for some systems. This will occur, for example, for a mixture of gases in which the components of the system have lower partial pressures than those in the surrounding atmosphere. Increasing their partial pressures after separation through semipermeable membranes will re= quire work to be done on them, $\left(W^{\circ}<0\right)$, in the presence of otherwise positive work $(W>0)$. In such cases the coupling of the system to the passive environment through semipermeable membranes may become questionable.

Some authors call the terms in eqn. $(39 a, b)$ by a separate name--essergy-meaning by it the essence of energy. I find it difficult to agree that this quantity is an essence of anything, least of all of energy, for the same reason that I objected to "anergy" in Section 9. Besides, I deplore the proliferation of terms.

tIt is immaterial whether the equilibrium is constrained or not, as long as the same composition is stipulated for $\mathrm{G}_{\mathrm{k}}^{*}$. Unconstrained equilibrium must be postulated for optimum work. 


\section{Short glossary of terms}

Sober common sense convinces that only a handful of special terms is needed in this field. Here is my selection:

available work $\left\{W^{\circ}\right\}$

dead state

\{supersc. *\}

dissipated work

$\left\{W^{O}-W=Q^{0}-Q\right\}$

$$
\left\{\Phi=T^{*} \Theta\right\}
$$

energy $\{\mathrm{U}\}$.

entropy production

$\{\theta\}$

exergy $\{E\}$

membrane pressure

$\{\tilde{\mathrm{P}}\}$ optimum work achievable by a hypothetical reversible process between two specified states of a specified system which interacts in a specified manner with the passive environment

a state of specified equilibrium reached by a system which interacts in a specified manner with the passive environment

difference between work performed by a system during irreversible process $1 \rightarrow 2$ and a hypothetical reversible process between the same end states

a much abused term nowadays (especially in the media): here it designates the thermodynamic function

$$
\mathrm{u}+\frac{1}{2} v^{2}+\mathrm{gz}
$$

where $u$ is the specific internal, energy of a system-a "constitutive" potential function whose absolute value at any single state has no physical meaning, because it contains an arbitrary additive constant

entropy difference of the union of thermodynamic system and passive environment measured between two given states 1 and 2 of the system; preferred absolute measure of irreversibility

the exergy of a specified system at a specified state is the available work obtainable in process to final state which is one of specified equilibrium with the passive environment (dead state)

pressure achieved by a pure species when in isothermal equilibrium with a mixture across a semipermeable membrane pervious only to this species; (equal to partial pressure in a mixture of perfect gases)

passive environment idealized model of terrestrial atmosphere pictured as environment $\left\{\mathrm{T}^{*}, \mathrm{P}^{*}, \mu_{i}^{* *}\right\}$ union of (i) reservoir of energy, (ii) reservoir of volume; (iii) reservoir of matter; its intensive state defined by temperature $T^{*}$, pressure $P^{*}$ and chemical potentials $\mu_{i *}$ of specified species remains unaffected by interactions with system 
reservoir

resource

utilization factor $\{n\}$ idealized component of model of terrestrial atmosphere (passive environment) characterized by constant intensive state, by a permanent state of internal equilibrium (zero relaxation time) and an inability to perform irreversible processes.

material found in nature (or created artificially) in a state of disequilibrium with the passive environment

ratio of actual work, $W$, to available work, $w^{\circ}$, in forward operation $(W>0)$ and its inverse in reyerse operation $(W<0) ; n=W / W^{\circ}$ or $n=\left|W^{0}\right| /|w|$; state 2 may be stipulated for it; preferred relatiye measure of irreversibility.

Acknowledgements

I express appreciation to my graduate student David Dickinson who played an active role in the research described here. His critical and responsiye attitude enabled me to identify and to resolve many of the points raised in the lecture. Mr. Dickinson checked the equations and read the proofs. He also assumed the responsibility for the references.

The work was accomplished with financial assistance under Contract EY-76-S-02-4.051.A001 awarded to Brown University by the Division of Geothermal Energy of the U.S. Department of Energy with Mr. C. McFarland acting as program manager. This work is a logical continuation of the report entitled, "Available Work in Geothermal Energy" which forms part of the forthcoming "Sourcebook on the Production of Electricity from Geothermal Energy".

The immediate trigger to undertake this synthesis came in the form of Professor A.B. Cambel's invitation to lecture at this Workshop. I gratefully acknowledge his confidence.

\section{References}

1. Gouy, M., "Sur l'energie utilisable", Journal de Physique 8 (1889) pp. 501518.

2. Gibbs, J.W., "A method of geometrical representation of the thermodynamic properties of substances by means of surfaces", Trans. Conn. Acad. Arts Sci. 1873, II, p. 382. The collected works of J. Willard Gibbs, Longmans Green, London, 1931, I, p. 33.

3. Gibbs, J.W., "On the equilibrium of heterogeneous substances", Trans. Conn. Acad. Arts Sci. 1875, III, p. 131. The collected works of J. Willard Gibbs, Longmans Green, London, 1931, I, p. 77. 
4. Haywood, R.W., "A critical review of the theorems of thermodynamic availability, with concise formulations".

"Part I. Availability", Jour. Mech.. Eng. Sci. 16, (3), (1974), pp. 160-173.

"Part II. Irreversibility", Jour. Mech. Eng. Sci. 16, (4), (1974), pp. 258-267.

5. Tait, P.G., "Sketch of thermodynamics", Edinburgh University Press, 1898.

6. Maxwel1, J.C. "Theory of heat", 1-st ed., Longmans Green, London, 1871.

7. Thomson, William (Lord Kelvin), "On thermodynamic motivity", Phil. Mag. I, (series V) (1879).

8. Stodola, A., "Die kreisprozesse der gasmaschine", Z. Ver. dt. Ing. 42, (1898), p. 1088 .

9. Stodola, A., "Die dampfturbinen", Springer Verlag, Berlin, 1905. English. translation by L.C. Loewenstein, McGraw-Hill, 1927.

10. Jouguet, M.E., "Le théorème de M. Gouy et quelques-unes de ses applications", Revue Mec., Paris 20, (1907), pp. 213-238.

11. Keenan, J.L., "A steam chart for second law analysis", Mech.' Eng. 54, (1932), pp. 195-204.

12. Darrieus, G., "The rational definition of steam turbine efficiencies", Engineering 130, (1930), pp. 283-285.

13. Baehr, H.D., "Thermodynamik", 1-st ed., Springer Verlag, Berlin, 1962.

14. Rant, Z., "Exergie, ein neues wort fur "Technische Arbeitsfahigkeit", Forsch.-Ing. -Wes. 22, (1956), p. 36.

15. Bosnjakovic, F., "Technische thermodynamik", Steinkopf, 1935, I, English. translation by P.L. Blackshear Jr., Holt, Rinehart \& Winston, NY 1965.

16. Evans, R.B., "A proof that essergy is the only consistent measure of potential work (for chemical systems)", Ph.D. thesis, Dartmouth College, Hanover, NH, 1969. University Microfilms 70-188, Ann Arbor, Michigan.

17. Szargut, J., and Petela, R., "Egzergia", Wyd. Naukowo-Techn., Warsaw, 1965.

18. Madejski, J., "Termodynamika techniczna", Rzeszow, 1977.

19. Kirillin, V.A., Sychev, V.V. and Sheindlin, A.E., "Engineering thermodynamics", Mir Públishers, Moscow, 1976.

20. Callen, H.B. "Thermodynamics", Wiley, NY, 1960. 
21. Kestin, J., "A course in thermodynamics", 1966 repr. 19.78 Blaisdel1, Wal tham; Hemisphere, Washington, Vol. I., Chap. 13.

22. Kestin, J., Idem, 1968 repr. 1978, Vol. II, Chap. 24.

23. Kestin, J., Idem, Vo1. I, Chap. 5 and Vo1. II, Chap. 21.

24. Bataille, J., and Kestin, J., "General forms of the dissipation inequality", Jour. Non-Equilibrium Thermodyn. 1, (1976), pp. 25-31.

25. Kestin, J., "Available work in geothermal energy", Brown Univ. Rep. No. CATMEC/20, DOE No. C00/4051-25, July, 1978, Providence, R.I.

26. U.S. Geological Survey, "Assessment of geothermal resources in the United States--1978", Geological Circular 790.

27. Kestin, J., "A course in thermodynamics", 1966 reprint 1978 Blaisdell, Waltham; Hemisphere, Washington, I, Chap. 5.

28. Kestin, J., Idem, Chap. 14. 